\title{
The influence of non-cooled exhaust gas recirculation on the diesel engine parameters
}

\begin{abstract}
This paper presents the results of the diesel engine research on the energy performance, components of exhaust gases and smoke and parameters related to the supply system for VW 1.9 TDI working in 2 modes: with standard, non-cooled EGR system, and without this system. All of measurements were carried out on the some engine speed - $2000 \mathrm{rpm}$ (speed of maximum engine torque) and various engine loads. It was found that the serial engine control unit switches the EGR system off above $150 \mathrm{Nm}$ engine load $($ Mo max $=295 \mathrm{Nm})$. In this range of load the engine running with EGR is characterized by higher fuel consumption (lower total efficiency) ca. 5\%, compared with engine without EGR. Concentration of $\mathrm{NO}_{x}$ in exhaust gases was lower up to $45 \%$ but, at the same time, exhaust gas smoke and concentration of carbon oxides were strongly increasing. It can be seen that EGR system increases the temperature (up to $110^{\circ} \mathrm{C}$ ) and changes the composition of air-exhaust gas in the intake manifold. One of reason of this fact is self-changing start of injection. Additional effect of EGR is lower air pressure behind turbocharger, because the flow of exhaust gases (into EGR) is taken before the turbine.
\end{abstract}

Key words: diesel engine, exhaust gases, EGR

\section{Introduction and methodology of research}

In the domain of diesel engines, the emission of carbon monoxide $(\mathrm{CO})$ and unburned hydrocarbons $(\mathrm{HC})$ does not pose a serious threat to the development of their structure. It is different from the emission of nitrogen oxides $\left(\mathrm{NO}_{\mathrm{x}}\right)$ and particulates matter (PM) [1]. One of the common methods used by manufacturers of internal combustion engines is to reduce the $\mathrm{NO}_{\mathrm{x}}$ concentration in exhaust gases by means of external exhaust gas recirculation (EGR). In a large number of engines, this is a non-cooled EGR [3, 4]. However, the question is whether the use of EGR significantly affects other parameters of engine operation (directly or indirectly), and if so, how it affects the engine itself and its user.

From the review of domestic and foreign literature it is clear that the effect of EGR on diesel engine performance is quite well studied. However, most publications do not deal with the energy parameters and composition of the engine exhaust gases (working with/without EGR) with the parameters of the indicator graphs and the rate of heat release. Detailed analysis of bibliographic data would exceed the volume potential of this publication. The purpose of the author was to determine the impact of the EGR on the specific operation of the propulsion engine (VW 1.9TDI AJM) tested, inter alia because of the use of this engine for other research purposes.

This article, and its second part, on the impact of EGR on the parameters of indicator graphs and the rate of heat release in the engine cylinder, is an attempt to answer this question. The study was carried out using the popular VW 1.9 TDI engine in the AJM version (with injection unit), popular in Europe, in passenger cars and light commercial vehicles. This article describes the influence of engine load (at max torque speed $2000 \mathrm{rpm}$ ) on the basic engine parameters and exhaust composition. In the study were used Schenk's engine dynamometer, AVL Fuel Balance and AVL Bench Emission System CEB II for measuring the concentration of gaseous components. In addition, the air temperature collected by the engine, the air temperature behind the turbocharger, the inter-cooler and the intake manifold (behind the EGR valve) were measured. The exhaust gas temperature was measured before and after the turbocharger. For comprehensive analysis, the impact of the engine load on the boost pressure and the onset of fuel injection. In the second part of the article, the AVL Indimeter 617D was also used to determine and analyze the fastchanging pressure in the engine cylinder (as a function of the engine crankshaft rotation angle) and to calculate the rate of heat release. In each of these cases the engine worked in two operating modes:

- MODE I - with factory preset of EGR,

- MODE II - without exhaust gas recirculation (EGR).

\section{Experimental}

\subsection{Energy parameters of the engine}

A common parameter used to determine the current degree of exhaust gas recirculation is the percentage of opening of the EGR valve. The value of this parameter was measured using the VCDS diagnostic interface communicating with the engine controller via the OBD2 connector of the engine used. Changes to the EGR valve opening as a function of engine load (torque Mo) are shown in Fig. 1. It can be seen that the highest values of exhaust gas recirculation correspond to the lowest engine loads. Although the $\mathrm{NO}_{\mathrm{x}}$ concentration in the exhaust then is not high but the low fuel consumption makes it possible to replace the clean air (consumed by the engine) with significant amounts of exhaust gas. With a higher engine load (over $100 \mathrm{Nm}-$ about $1 / 3$ of the maximum torque), the EGR valve turns off by the engine controller to completely disable the exhaust gas recirculation at $175 \mathrm{Nm}$. High engine load is characterized by high $\mathrm{NO}_{\mathrm{x}}$ concentration and exhaust gas recirculation would be most needed at that time, however, high fuel consumption requires large amounts of clean air, not mixed with exhaust gases within the EGR. Data shown in Fig. corresponds to the operation of the engine according to I MODE - factory setting of EGR. In II MODE, the percentage of opening of the EGR valve is $0 \%$. 


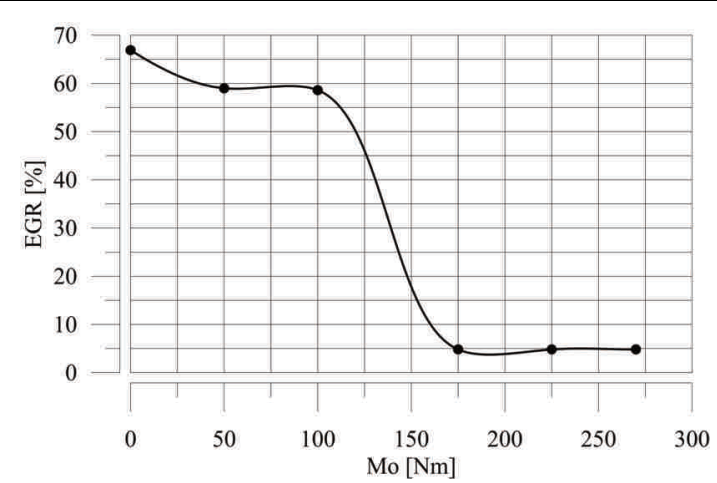

Fig. 1. Influence of engine load on factory change of opening of exhaust gas recirculation valve (EGR)

A parameter that clearly shows the difference between the engine operation with and without the EGR system is the temperature at the intake manifold (Fig. 2). During operation of the engine without exhaust gas recirculation, the temperature of the intake manifold slightly increases over the entire engine load range, not exceeding $55^{\circ} \mathrm{C}$. This is caused by an increase in the charge pressure then. When operating the engine with the factory-set EGR, can see that the maximum EGR valve opening temperature is up to $108^{\circ} \mathrm{C}$. Only when the engine load increases, when the EGR valve is closed by the engine controller, the temperature of the intake manifold approaches the values achieved without this system. It can therefore be stated that the use of the EGR system significantly influences the temperature of the intake manifold. This phenomenon is due to the fact that when the EGR valve is open, hot gases are introduced into the intake manifold, which cause the temperature to rise.

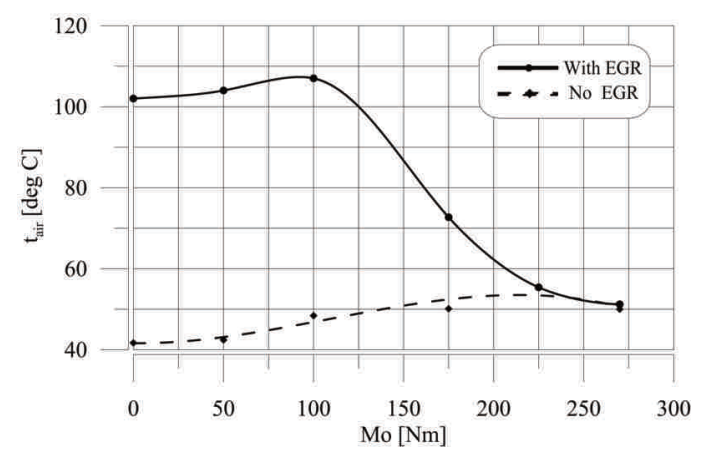

Fig. 2. Influence of the engine load on the temperature inside the intake manifold of engine operating with/without EGR

A large increase in temperature in the engine intake manifold working with the factory opening of the EGR valve compared to the EGR switched off is a disadvantage because this temperature is added to the combustion temperature. For this reason, the cooled EGR system, used in modern engine designs, reduces the $\mathrm{NO}_{\mathrm{x}}$ concentration in the exhaust gas more effectively than not cooled EGR does.

The operation of the exhaust gas recirculation also affects the variation of the fuel gas temperature before the turbocharger, as a function of the engine load. In the area of small and medium engine loads, when the controller makes the EGR system on, the exhaust gas temperature before the turbine is significantly lower. This is due to the fact that a large proportion of the exhaust, within the EGR, it is deliv- ered to the intake manifold, so the kinetic energy of the exhaust before the turbine decreases then. Because the measure of kinetic energy of gas is, among others, the temperature of this gas, the reduction of exhaust gas energy with the EGR switched on, leads to a reduction of the exhaust gas temperature in front of the turbine, as illustrated in Fig. 3.

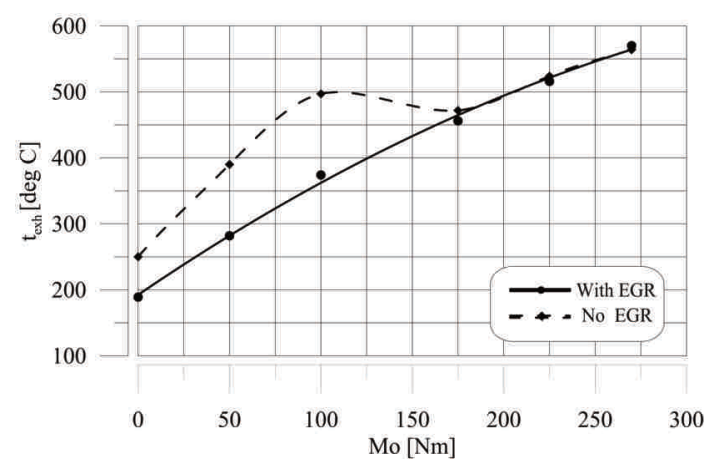

Fig. 2. Influence of the engine load on the exhaust gas temperature before the turbine of engine operating with/without EGR

The turbine exhaust gas stream (energy) is reduced by the exhaust gas flow to the engine intake manifold working with the open EGR valve [2]. For this reason, the boost pressure $\left(\mathrm{p}_{\mathrm{d}}\right)$ in the engine running with the EGR system switched on is lower than the air pressure behind the engine charger running without EGR. This is shown in Fig. 3.

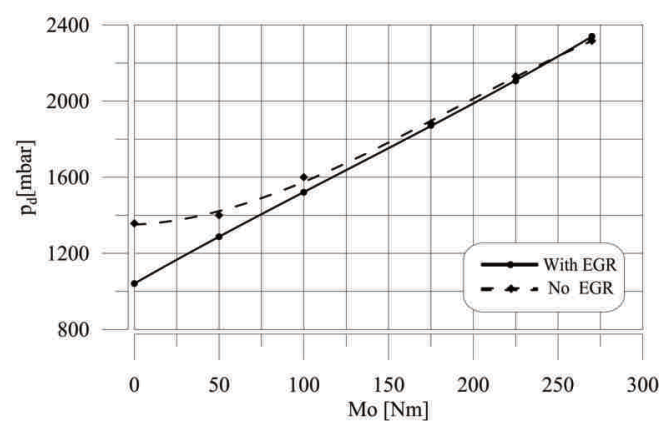

Fig. 3. Influence of engine load on the air pressure after the turbocharger of engine operating with/without EGR

Obviously, the difference in air pressure behind the charger for the engine running with/without EGR also results in other air temperatures behind the turbocharger, as shown in Fig. 4.

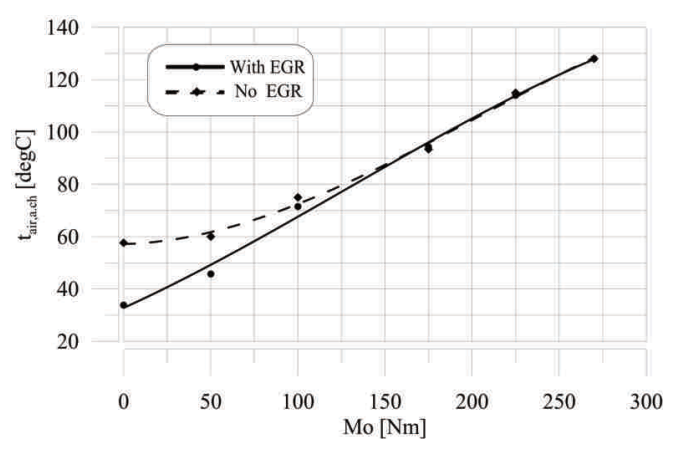

Fig. 4. Influence of the engine load on the air temperature after the turbocharger of engine operating with/without EGR 
The reduced air temperature behind the compressor for the exhaust gas recirculation engine is of no importance since, as shown in Fig. 2, the air in the intake manifold blended with hot exhaust gases and the air temperature taken into the engine cylinder is significantly higher than that of the engine running without EGR.

Increasing the temperature of the intake manifold gas and lowering the pressure behind the turbocharger (reduction of charge density) and, above all, the lower purity air stream consumed by the engine running the exhaust gas recirculation, naturally reduces the excess air ratio value (Fig. 5). With heavy engine loads (175 Nm and higher), the $\lambda$ values are the same for both engine operating modes, as the EGR valve closes with the engine controller. On the other hand, with lower engine loads, the EGR effect would have to be separated into two stages of engine operation: idle run and partial loads.

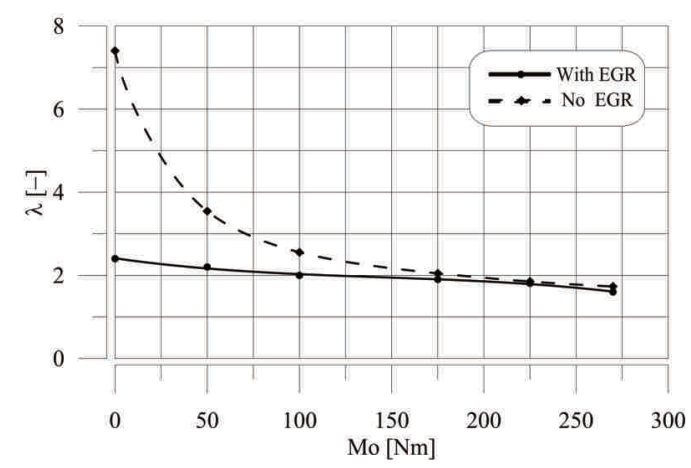

Fig. 5. Influence of the engine load on the excess air ratio $\lambda$ for engine operating with/without EGR

For idle run $(\mathrm{Mo}=0 \mathrm{Nm})$ in the cylinder of the diesel engine operating without the EGR system, in the combustion process the huge mass of air is disproportional to the low fuel dose $(\lambda=7.4)$. This is an unfavorable composition of the fuel-air mixture due to the engine's thermal efficiency. In addition, so much air, which largely does not take part in the oxidation of the fuel, is a thermodynamic ballast, which unnecessarily receives part of the heat intended for performance and lifts the heat from the exhaust. This is an undoubted waste of energy. Therefore, for idle run, adding a portion of the exhaust to the air in the intake manifold reduces the fuel consumption (Fig. 6) by decreasing the volumetric efficiency $\eta_{\mathrm{v}}$ (Fig. 7), which in turn reduces the excessively high value of the excess air ratio $\lambda$ (Fig. 5).

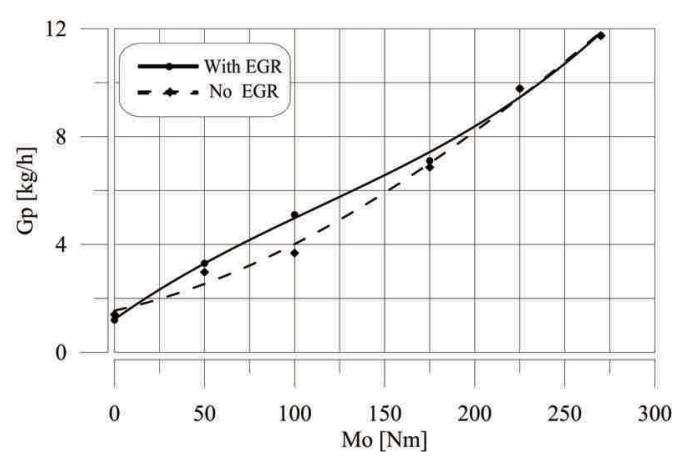

Fig. 6. Influence of the engine load on the fuel consumption $\mathrm{Gp}$ for engine operating with/without EGR
With partial engine loads (in this case, up to $175 \mathrm{Nm}$ ) the use of EGR, resulting in a reduction in the amount of clean air in the engine cylinder (due to the need of reducing the $\mathrm{NO}_{\mathrm{x}}$ concentration in the exhaust gases), worsens the course of the combustion process. This is clearly evident in the overall efficiency of the engine running with/without EGR (Fig. 8). As the result of the work of EGR, with engine load of $50 \mathrm{Nm}$, the overall efficiency of the engine running without EGR is reduced from $32 \%$ to $25 \%$ after switching the exhaust gas recirculation on. Percentage reduction in overall efficiency ( 22 percentage points) is automatically means an increase in fuel consumption (Fig. 6). This should not be surprising, since the structural or regulatory methods that reduce $\mathrm{NO}_{\mathrm{x}}$ emissions in the exhaust gases unfortunately have an adverse effect on the overall efficiency of the engine, too.

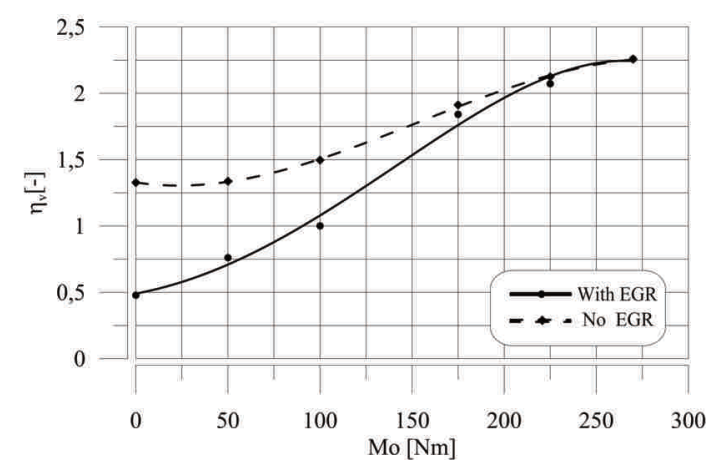

Fig. 7. Influence of the engine load on the volumetric efficiency $\eta_{v}$ of engine cylinder for engine operating with/without EGR

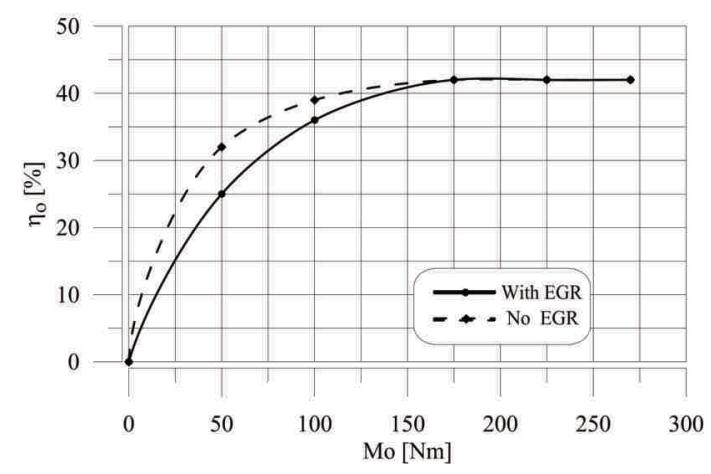

Fig. 8. Influence of the engine load on the engine efficiency $\eta_{\mathrm{o}}$ for engine operating with/without EGR

The research on the impact of the exhaust gases recirculation on the composition of the exhaust gases was started from the $\mathrm{NO}_{\mathrm{x}}$ concentration in the exhaust gas, because that is what the EGR system was created for. From the data shown in Fig. 9, it is clear that within the engine load range at which the factory EGR operates, the $\mathrm{NO}_{\mathrm{x}}$ concentration in the exhaust gases is reduced by up to $45 \%$ compared to that of the non-EGR engine.

Since the impact of the engine load on $\mathrm{NO}_{\mathrm{x}}$ concentration in the exhaust gas is very high $(60 \mathrm{ppm}-1200 \mathrm{ppm})$, to further analyze the effect of EGR on the concentration of this exhaust gas component, see below (Fig. 9b) bar charts separately for selected engine loads. 


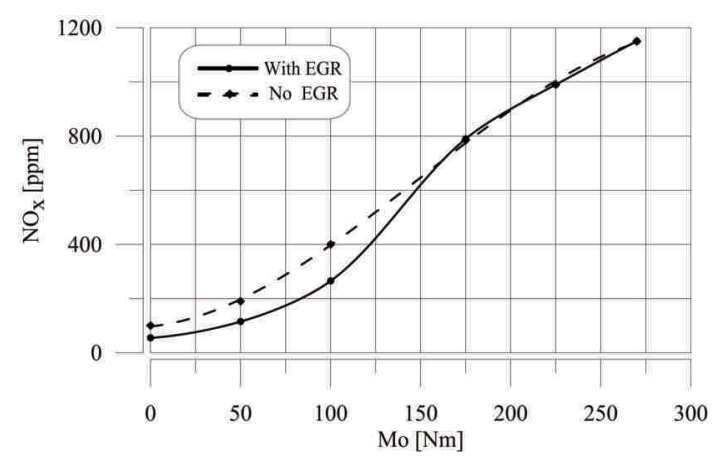

Fig. 9. Influence of the engine load on the $\mathrm{NO}_{\mathrm{x}}$ concentration in exhaust gases for engine operating with/without EGR
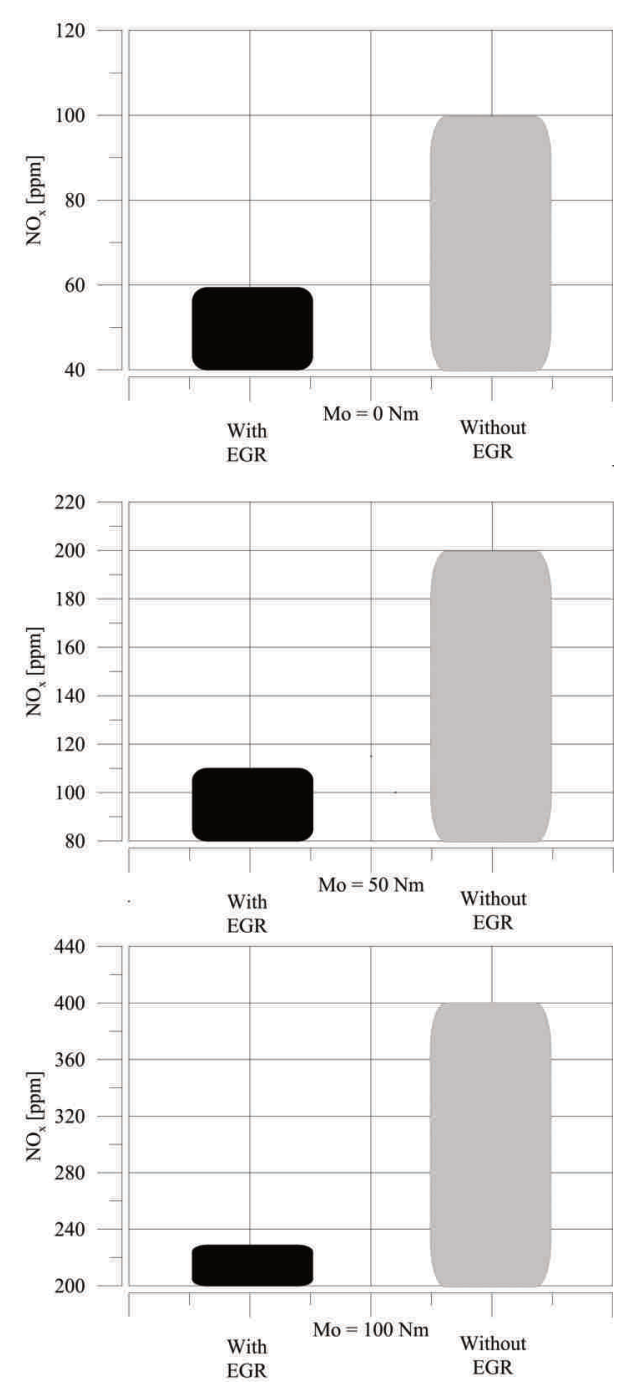

Fig. 9b. Influence of the engine load (within the range of the EGR activity) on the $\mathrm{NO}_{\mathrm{x}}$ concentration in exhaust gases for engine operating with/without EGR

Unfortunately, as mentioned earlier, in terms of high engine loads, where the concentration of nitrogen oxides is the greatest, the engine controller must shut the system down because of the high demand for clean air used to burn high fuel dose.

As a matter of principle, exhaust gases recirculation might seem to be the result of the reduction of $\mathrm{NO}_{\mathrm{x}}$ concentration in the exhaust gases for an EGR engine only because of the limited availability of oxygen, oxygenating the nitrogen from the air. Of course, this is not just the EGR mechanism. A more detailed analysis of this phenomenon will be carried out in the second part of the article, which shows the effect of EGR on the course of indicator graphs and rate of heat release in the engine cylinder working with/without exhaust gas recirculation.

Carbon monoxide is a typical incomplete combustion product that comes into being by global or local oxygen deficiency. Since the exhaust gases recirculation is intended to reduce the amount of oxygen in the engine cylinder, it must therefore lead to an increase in the CO concentration in the engine exhaust gases. This is shown in Fig. 10.

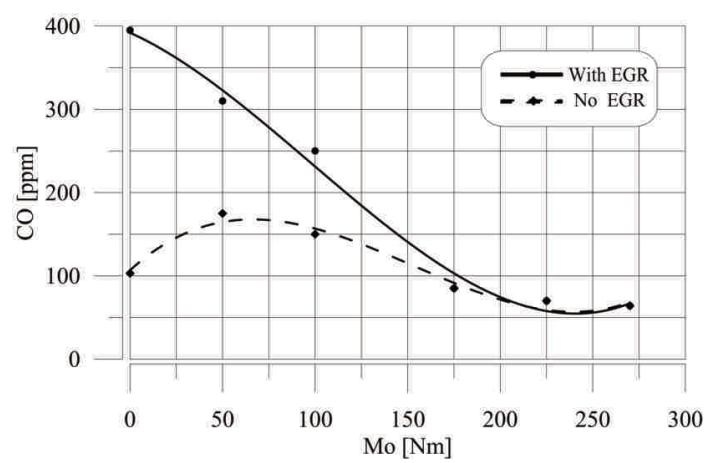

Fig. 10. Influence of the engine load on the $\mathrm{CO}$ concentration in exhaust gases for engine operating with/without EGR

As far as the engine load, at which the EGR valve is open is concerned, the $\mathrm{CO}$ concentration in the exhaust gases is greater by $75-40 \%$ compared to the carbon monoxide concentration in the exhaust gases of the non exhaust gas recirculation engine. However, the increase in $\mathrm{CO}$ concentration in the exhaust of the contemporary $\mathrm{CI}$ engine is not a problem, as these engines are equipped with an oxidation catalytic convertor which, at values of $\lambda>2$ (Fig. 5) effectively catalyzes carbon monoxide.

In the exhaust gas used in the testing of the VW 1.9 TDI engine, under test conditions, the unburned hydrocarbons concentration, both with and without the EGR system varies from just a few dozen ppm. Of course, it is larger for an open EGR valve. This is mainly due to not limiting the amount of oxygen in the engine cylinder working with the EGR, which results in a reduction in combustion temperature. One reason for the lower maximum combustion temperature in the case of an EGR engine is the shortening of self-ignition delay $\left(\tau_{\mathrm{s}}\right)$, but the analysis of this phenomenon will be carried out in the second part of the article on the effect of EGR on the parameters of the graphs and the velocity of heat generation. As with the carbon monoxide concentration, unburned $\mathrm{HC}$ emissions do not pose a problem to those oxidation catalytic convertors operating at big excess air ratio $\lambda$. A more serious problem, however, is the effect of exhaust gas recirculation on the smoke exhaust of diesel engine. This is shown in Fig. 11.

This phenomenon is unfavorable because as the exhaust smoke increases, the emission of particulate matter (PM) increases too. This is typical of most engine methods that reduce $\mathrm{NO}_{\mathrm{x}}$ concentration in exhaust gases. Reducing the maximum combustion temperature to reduce $\mathrm{NO}_{\mathrm{x}}$ emis- 
sions also reduces the efficiency of the combustion of the particulate matter generated in the engine cylinder, which increases the PM emissions in the exhaust gas of the diesel engine. Of course, in another stage of the combustion process, nitrogen oxides are formed (mainly in the kinetic combustion stage), and in another stage, the resulting PM particles are burned up, but the analysis of these phenomena is shown in the second part of this article.

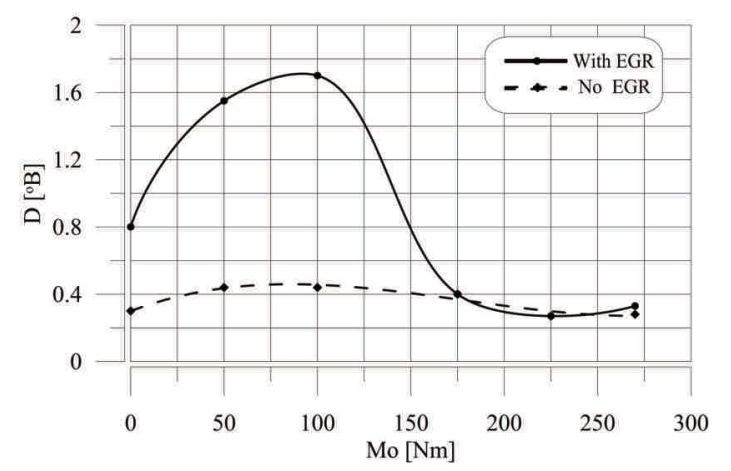

Fig. 11. Smoke exhaust D of diesel engine operating with/without EGR

\section{Conclusions}

In conclusion, the use of non-cooled exhaust gas recirculation in a diesel engine (compared to an engine without EGR) results in:

- on the idle run of the engine - reduced hourly fuel consumption,

- as regards small and medium loadings of the engine, EGR increases an hourly fuel consumption, which results in a reduction in the overall efficiency of the engine by up to $20 \%$ compared to the engine without exhaust gas recirculation,
- as regards engine load where the exhaust gases recirculation system is turned on, a clear EGR effect reducing the nitrogen oxide concentration in the exhaust gases (up to $45 \%$ ) can be observed. However, at the highest engine loads, when nitrogen oxides are generated the most, it is not possible to use an exhaust gas recirculation system (due to the high engine demand for large amounts of air needed for burning a large dose of fuel)

- applying an EGR system increases the CO concentration by as much as $70 \%$ compared to engine operation with closed exhaust gases recirculation valve. However, in CI engines this is not a problem, due to the high efficiency of the catalytic oxidation reactors,

- in CI engines, the decrease in nitrogen oxide emissions is accompanied by increasing smoke exhaust and particulate PM emissions. With the exhaust gases recirculation system, an increase of over $70 \%$ is observed. This requires the use of post-processed methods for purifying particulate matter such as FAP or DPF filters,

- the exhaust gases recirculation system is a method that performs its function in the small area and average engine load with respect to the reduction of NOx concentration in exhaust gases at this point. The EGR, however, adversely affects a number of engine energy parameters and the concentration of other harmful exhaust gases,

- the comparison of the indicator graphs and the rate of heat release in the engine cylinder operating with/without the EGR will allow a deeper analysis of the causal effect of exhaust gas recirculation on the actual diesel engine work cycle (second part of the article).

\section{Nomenclature}
CI compression ignition
$\mathrm{CO}$ carbon monoxide
D exhaust smoke
EGR exhaust gas recirculation
$\mathrm{G}_{\mathrm{p}}$ fuel consumption
$\mathrm{HC}$ unburned hydrocarbons
Mo engine torque
$\mathrm{NO}_{\mathrm{x}}$ nitrogen oxides
PM particulate matter

$\begin{array}{ll}\mathrm{p}_{\mathrm{d}} & \text { air pressure after the turbocharger } \\ \mathrm{t}_{\text {air }} & \text { temperature inside the intake manifold } \\ \mathrm{t}_{\text {air,a.ch }} & \text { air temperature after the turbocharger } \\ \mathrm{t}_{\mathrm{exh}} & \text { exhaust gas temperature before the turbine } \\ \lambda & \text { excess air ratio } \\ \eta_{\mathrm{v}} & \text { volumetric efficiency of engine cylinder } \\ \eta_{\mathrm{o}} & \text { total efficiency of engine cylinder } \\ \tau_{\mathrm{s}} & \text { self-ignition delay }\end{array}$

[3] MYSZKOWSKI, S. Recyrkulacja spalin w silnikach cz.1. Dodatek techniczny do wiadomości Inter Cars S.A. 2010, 35.

[4] CIEŚLIK, W., BOROWSKI, P., PIELECHA, I. et al. System recyrkulacji spalin we współczesnych konstrukcjach silnikowych. Logistyka. 2014, 3.

\section{Bibliography}

[1] MERKISZ, J. Ekologiczne problemy silników spalinowych. Tom 1. Wydawnictwo Politechniki Poznańskiej. Poznań 1998.

[2] HEYWOOD, J.B. Internal combustion engine fundamentals. McGraw-Hill Book Company, Series In mechanical engineering, USA, 1988.

\section{.}

